\title{
Electrochemical polymerization of ambipolar carbonyl-functionalized indenofluorene with memristive properties
}

\author{
Viviana Figà $^{\mathrm{a}, *}$, Hakan Usta $^{\mathrm{b}, * *}$, Roberto Macaluso ${ }^{\mathrm{c}}$, Ulrike Salzner ${ }^{\mathrm{d}}$, Mehmet Ozdemir ${ }^{\mathrm{b}}$, \\ Bohdan Kulyk $^{\mathrm{e}}$, Oksana Krupka ${ }^{\mathrm{f}}$, Maurizio Bruno ${ }^{\mathrm{g}}$ \\ ${ }^{a}$ Euro-Mediterranean Institute of Science and Technology (IEMEST), Via Michele Miraglia 20, 90139, Palermo, Italy \\ ${ }^{\mathrm{b}}$ Materials Science and Nanotechnology Engineering - Abdullah Gul University, 38080, Kocasinan, Kayseri, Turkey \\ ${ }^{\mathrm{c}}$ Thin Films Laboratory (TFL), Università degli Studi di Palermo, Dipartimento di Ingegneria, Viale delle Scienze (Ed.9), 90128, Palermo, Italy \\ ${ }^{\mathrm{d}}$ Department of Chemistry, Bilkent University, Bilkent, 06800, Ankara, Turkey \\ ${ }^{\mathrm{e}}$ Department of Physics - Ivan Franko National University of Lviv, 50, Dragomanova Str, Lviv, UA-79005, Ukraine \\ ${ }^{\mathrm{f}}$ Department of Chemistry, Taras Shevchenko National University of Kyiv, 60 Volodymyrska, 01033, Kyiv, Ukraine \\ ${ }^{\mathrm{g}}$ Dipartimento di Scienze e Tecnologie Biologiche, Chimiche e Farmaceutiche, Università di Palermo, Viale Delle Scienze, Parco D’Orleans II, 90128, Palermo, Italy
}

\section{A R T I C L E I N F O}

\section{Keywords:}

Indenofluorene derivatives

Electrochemical polymerization

Organic semiconductors

Organic memristors

\begin{abstract}
A B S T R A C T
Carbonyl-functionalized indenofluorene was electropolymerized with a high faradaic efficiency of $85 \%$ and the solid state properties of the resulting polymeric thin films were investigated. They displayed modular optical properties depending on their oxidation state. The approach used for inorganic semiconductors was applied to polyindeonofluorene derivative. Mott-Schottky analysis evidenced a switching from p-type to n-type electrical conduction, suggesting an ambipolar behaviour of the polymer. As an application, flexible organic memristors were fabricated and resistive switching properties were observed.
\end{abstract}

\section{Introduction}

Conjugated polymers constitute a highly promising class of functional materials having wide range of applications in organic optoelectronics. They demonstrated encouraging performances when used as electro-active films in organic and hybrid solar cells, organic field-effect transistors, biosensors, organic light-emitting devices and so on [1-6]. The structural versatility of polymer $\pi$-backbones and their tunable redox states provide them advantageous optoelectronic properties. In particular, changing the oxidation state of a polymer $\pi$-backbone can significantly modulate electrical and optical responses, which is exploited in several applications including electrochromic devices. The redox state variation also modulates their non-linear optical properties $[7,8]$ making polymers applicable in laser and optical memory fields. In this respect, electrochemistry plays a fundamental role in both deposition and characterization of polymeric films. By electrochemical methods, it is indeed possible to copolymerize two different monomers with the goal of realizing copolymers with different and better properties than the respective homopolymers [9,10]. Among numerous polymeric conjugated systems studied to date, polyindenofluorenes attracted attention originally due to their good chemical stability and high luminescence quantum efficiency [11]. Later, numerous molecules embedding indenofluorene building blocks were designed and synthesized using efficient synthetic approaches. Indenofluorene (IF) derivatives with good photostability were used as electron donors with $\mathrm{C}_{70^{-}}$ based electron acceptors in organic solar cells, which yielded high open circuit voltage and power conversion efficiency of 3\% [12]. Some research groups produced small molecules from IF, with wide band gaps to replace fullerenes in organic photovoltaics [13]. Thirion et al. [14] synthesized dispiro (fluorine-9-11'-indeno $(2,1 \mathrm{a})$ fluorene-12',9"-fluorenone) and 11,12-dihydroindeno [2,1a]fluorine building blocks and deposited their polymers by using anodic electropolymerization method. They also developed other $\pi$-systems based on dispirofluoreneindenofluorene and studied their potential applications in organic light emitting diodes (OLED), which resulted in blue/violet fluorescence with quantum yields of $30-80 \%$ [15]. Both single-layered and multilayered light-emitting devices configurations were developed [16]. Similar IF-based blue fluorescent compounds were employed in multilayered OLEDs showing a luminous efficiency of $12.2 \mathrm{~cd} \mathrm{~A}^{-1}$, a power efficiency of $6.08 \mathrm{~lm} \mathrm{~W}^{-1}$, and an external quantum efficiency of $7.84 \%$ at $20 \mathrm{~mA} \mathrm{~cm}^{-2}$ [17]. On the other hand, IF-based molecules and polymers were used as solution-processable semiconductors in organic field-

\footnotetext{
* Corresponding author.

** Corresponding author.

E-mail addresses: vivianafiga@iemest.eu (V. Figà), hakan.usta@agu.edu.tr (H. Usta).
} 
effect transistors (OFETs). To this end, Usta, Facchetti, Marks et al. $[18,29]$ designed and synthesized high performance $p$-type, $n$-type, and ambipolar semiconductors with good processability and air stability for use in field-effect transistors. In particular, carbonyl-functionalized molecule 2,8-bis(5-(2-ethylhexyl)thien2-yl)indeno [1,2-b]fluorine6,12-dione showed ambipolar semiconductivity, and dicyanovinylenefunctionalized molecule 2,8-bis(5-(2-octyldodecyl)thien2-yl)indeno [1,2-b]fluorine-6,12-dicyanovinylene showed n-channel semiconductivity [19-21]. Despite all these studies focusing on indenofluorene-based OFET and OLED devices, their employment in memristive devices, which has potential applications ranging from information storage to neuromorphic systems, has not been yet reported [22,23]. To date, most efforts were directed to inorganic materials-based memristors $[24-26,45]$. In order to introduce to memristive devices mechanical flexibility and structural versatility, which are essential for flexible and wearable electronics, new organic materials need to be developed. In the last years, only a few polymers, such as polyaniline, polythiophene, poly (ethyleneoxide), have been reported as materials employed for the fabrication of single component - organic memristors. They required, however, a forming cycle to be operative as memory devices, and have shown high $\mathrm{R}_{\mathrm{OFF}} / \mathrm{R}_{\mathrm{ON}}$ ratios only in controlled atmosphere conditions or after sealing the devices [27,28]. The most performing organic memristors are currently based on blends, mixtures of polymers and hybrid materials and display a $\mathrm{R}_{\mathrm{OFF}} / \mathrm{R}_{\mathrm{ON}}$ ratio of about $10^{4}$ which is very competitive even with inorganic memristors. Unfortunately, this class of materials suffers of phase separation and ions aggregation that irreversibly affect the long term stability of the devices. In addition, hybrid materials employ expensive materials such as AuNP or graphene so that they are prohibitive for low cost devices applications. In this scenario, it is interesting exploring the potentiality of polyindenofluorenes for memristive devices applications.

In this work, we electropolymerize a carbonyl-functionalized IF derivative monomer (T-IFDK-T) having donor-acceptor-donor $\pi$-architectures and hydrogen-ended 2-thienyl positions, which yielded the donor-acceptor polymer poly(IFDK-T2). Note that previous attempts to synthesize this polymer from brominated monomer via conventional Yamamoto polymerization yielded totally insoluble solids [18]. Therefore, the electropolymerization approach presented here demonstrates as an effective way of realizing and characterizing poly(IFDKT2) polymeric systems. We also investigate the semiconducting, optical and electronic properties of the resulting polymeric thin films. These results are fundamental for identifying the possible applications of poly (IFDK-T2), considering that some devices operation and performance are influenced by the energy levels mutual position of the constituent materials. In addition, a morphological 3D analysis is carried out by Atomic Force Microscopy (AFM), and both surface structural assessment and thickness evaluation of the organic thin films are reported. Finally, poly(IFDK-T2) is employed for the fabrication and the electrical characterization of organic-based memristors.

\section{Materials and methods}

All reagents were purchased from commercial sources and used without further purification. Conventional Schlenk techniques were used and the syntheses of the monomer T-IFDK-T was carried out under nitrogen atmosphere in accordance with our previously published procedures starting from commercial building blocks [30]. The monomeric products were purified by column chromatography and characterized by ${ }^{1} \mathrm{H}$ and ${ }^{13} \mathrm{C}$ NMR spectroscopy to determine molecular structure and ensure high purity levels for electropolymerizations. The experimental procedure performed during syntheses is as follows:

Synthesis of 2,8-di-3-dodecylthiophene-indeno [1,2-b] fluorene6,12-dione (T-IFDK-T). The reagents IFDK- $\mathrm{Br}_{2}(0.28 \mathrm{~g}, 0.63 \mathrm{mmol}), 2$ tributylstannyl-3-dodecylthiophene $(0.415 \mathrm{~g}, 1.38 \mathrm{mmol})$ and $\mathrm{Pd}\left(\mathrm{PPh}_{3}\right)_{2} \mathrm{Cl}_{2}$ $(0185 \mathrm{~g}, 0.26 \mathrm{mmol})$ in anhydrous DMF $(40.0 \mathrm{~mL})$ were heated at $125^{\circ} \mathrm{C}$ under nitrogen $24 \mathrm{~h}$. The reaction mixture was cooled down to RT and evaporated to dryness. The crude product was then purified by column chromatography on silica gel using $\mathrm{CHCl}_{3}$ /hexanes (8:2) as the eluent to afford the pure product as a dark blue solid $\left(0.186 \mathrm{mg}, 38 \%\right.$ yield). ${ }^{1} \mathrm{H}$ NMR $\left(\mathrm{CDCl}_{3}\right)$ : 0.86-1.64 (m, 46H), $2.71(\mathrm{t}, 4 \mathrm{H}), 7.04(\mathrm{~d}, 2 \mathrm{H}, J=4.5 \mathrm{~Hz})$, 7.32 (d, 2H, $J=4.5 \mathrm{~Hz}), 7.61$ (d, $2 \mathrm{H}, J=7.5 \mathrm{~Hz}), 7.63$ (d, $2 \mathrm{H}, J=7.5 \mathrm{~Hz}$ ), 7.76 (s, 2H), 7.83 (s, 2H) ppm. ${ }^{13} \mathrm{C}$ NMR $\left(\mathrm{CDCl}_{3}\right): 14.4,22.96,29.1,29.6$, 29.7, 29.8, 29.9, 30.0, 31.2, 32.2, 116.3, 121.0, 124.6, 125.5, 130.1, 134.5, 136.1, 136.4, 136.8, 139.8, 140.0, 142.3, 145.9, 192.8 ppm.

Electrochemical polymerization of indenofluorene derivative $\mathbf{T}$ IFDK-T was performed in a traditional three-electrode cell under nitrogen pressure. Glassy carbon rod (diameter $=3 \mathrm{~mm}$ ) and indium-tin oxide/polyethylene terephthalate (ITO/PET) were used as working electrodes. Graphite rod and $\mathrm{Ag} / \mathrm{AgCl}(3.0 \mathrm{M} \mathrm{KCl})$ were used as counter and reference electrodes, respectively. Before each experiment, glassy carbon rod underwent a mechanical treatment with $1 \mu \mathrm{m}$ diamond and $0.05 \mu \mathrm{m}$ white alumina suspensions on suitable polishing pads. After the mechanical treatment, the glassy carbon rod was cleaned in deionized water and acetone in an ultrasonic bath. ITO/PET electrodes were sonicated in acetone. Dichloromethane (analytical standard, Sigma Aldrich) was used as electrodeposition solvent and $0.1 \mathrm{M}$ tetrabutylammonium hexafluorophosphate $\left(\mathrm{TBAPF}_{6}\right.$, for electrochemical analysis 99\%, Sigma Aldrich) was used as supporting electrolyte. The monomer concentration was $2 \times 10^{-4} \mathrm{M}$ for each experiment. Both potentiodynamic and potentiostatic techniques were applied for the electrochemical polymerization by means of an Ivium Vertex Potentiostat/Galvanostat. Following the thin-film electrodeposition process, both glassy carbon and ITO/PET working electrodes were washed with dichloromethane $\left(\mathrm{CH}_{2} \mathrm{Cl}_{2}\right)$ in order to remove residual monomers and supporting electrolyte. The electrochemical properties of the polymer were studied by cyclic voltammetry in a monomer free solution of $0.1 \mathrm{M} \mathrm{TBAPF}_{6}$ in $\mathrm{CH}_{2} \mathrm{Cl}_{2}$ starting from the open circuit potential, in a range between $+2.0 \mathrm{~V}$ and $-2.0 \mathrm{~V}$ with respect to the reference electrode. The potential scan rate was $100 \mathrm{mV} / \mathrm{s}$. AFM analysis was used to study the morphological features of the indenofluorene-based polymeric films (Solver P47 PRO (NT-MDT) atomic force microscope). AFM measurements were carried out by means of semi-contact method with the scanning frequency of $1 \mathrm{~Hz}$ by using a silicon probe, type NSG, with a tip radius of curvature of $10 \mathrm{~nm}$. AFM measurements were performed in air ambience. The processing of the experimental data and calculation of the surface morphology parameters were carried out by using Image Analysis software package (NTMDT). Furthermore, by using AFM the values of experimental film thickness were extracted and compared with the theoretical value.

Mott-Schottky (M - S) theory was applied to investigate the semiconducting features of the electropolymerized thin films. M - S analysis was performed by recording and elaborating potentiodynamic electrochemical impedance (PDEIS) spectra in a frequency range of $100 \mathrm{mHz}-10 \mathrm{kHz}$ by sweeping the potential value from $+1.0 \mathrm{~V}$ to $-1.0 \mathrm{~V}$ with respect to the reference electrode. During the measurements, the potential amplitude was $10 \mathrm{mV}$. A Faraday cage was used in order to minimize external electrical signals.

Optical characterization was carried out by recording the absorbance spectrum of the films as grown. Furthermore the electrochromic response of the polymer was investigated by applying different voltages, in a two-electrode cell endowed with quartz windows and having a path length of $10 \mathrm{~mm}$. The electrolytic solution was $0.1 \mathrm{M} \mathrm{TBAPF}_{6}$ in $\mathrm{CH}_{2} \mathrm{Cl}_{2}$. In particular, absorption spectra were recorded in the UV-Vis range at a scan rate of $100 \mathrm{~nm} / \mathrm{min}$ by means of a Varian DMS 90 Spectrophotometer and were corrected with respect to the ITO/PET substrate.

In order to verify the memristive behaviour of poly(IFDK-T2), large area devices consisting of a simple PET/ITO/poly(IFDK-T2)/Au sandwich structure were fabricated. The active area of each device (about $1 \mathrm{~mm}^{2}$ ) was determined by the top Au electrode, which was deposited onto PET/ITO/poly(IFDK-T2) via thermal evaporation by using a shadow mask. The underlying ITO film was used as the common bottom 
contact. All devices were electrically characterized by performing twoprobe I-V measurements by means of a custom developed electronic circuit connected to a Karl Suss probe station [25]. The measurements were performed at room temperature by applying a digital voltage ramp with steps of $50 \mathrm{mV}$ to the Au top contact, while keeping the bottom ITO contact grounded.

\section{Theory/calculation}

Structures of IFDK-2T oligomers with 1-4 units were optimized with density functional theory (DFT) employing the B3P86-30 hybrid functional with $30 \%$ of exact exchange and the $6-31 G^{*}$ basis set. This level of theory was chosen based on previous experience with large conjugated systems [30,31]. For the 4-IFDK-2T cation, we checked the polaron band positions which have strong charge transfer character also with the wB97X-D range-separated hybrid functional [51]. $\mathrm{C}_{12} \mathrm{H}_{25}$ chains were replaced with methyl groups. Solvent effects of dichloromethane were taken into account with the polarized continuum model (PCM) [32,33]. This does not only account for liquid solvent but also models the dielectric screening in the crystal and accounts therefore for most of the effects of crystal packing [47]. Ionization potentials (IP)s and electron affinity (EA) were calculated with the DSCF method as energy differences between neutral and ionized species. Anions of 4IFDK-2T with up to 5 additional electrons were evaluated with the 6$31+\mathrm{G}^{*}$ that contains diffuse functions. Diffuse functions increase EA1 by $0.25 \mathrm{eV}$. Structure optimization of the ions decreases IPs and increases EAs by about $0.2 \mathrm{eV}$. In the following we report mainly vertical IPs and EAs. Excited states were calculated with time-dependent (TD) DFT. The excitation spectrum of the 4-IFDK-2T cation is calculated on the optimized geometry of the cation. Charges were analysed with natural population analysis (NPA) [34]. The calculations were done with Gaussian 09 and 16 [35,36]. Spectra are plotted with GabEdit [37].

\section{Results and discussion}

\subsection{Synthesis and characterization}

The synthesis of hydrogen-ended T-IFDK-T monomer is shown in Scheme 1. Stille coupling of IFDK-Br2 with 3-dodecyl-2-trimethyltinthiophene in the presence of $\mathrm{Pd}\left(\mathrm{PPh}_{3}\right)_{2} \mathrm{Cl}_{2}$ catalysis in DMF yields T-IFDK-T in 38\% yield. The monomer was highly soluble in common organic solvents, which allowed its convenient purification by flash chromatography. Monomer structure and purity were characterized by ${ }^{1} \mathrm{H}$ and ${ }^{13} \mathrm{C}$ NMR spectroscopy, which confirmed the proposed molecular structure and indicated excellent purity.

\subsection{Electrochemical polymerization}

The electrochemical polymerization of (T-IFDK-T) was performed via anodic route by forming radical cations. In particular, the potential was swept, with a constant potential scan rate of $100 \mathrm{mV} / \mathrm{s}$, from the open circuit voltage $(0.27 \mathrm{~V} /(\mathrm{Ag} / \mathrm{AgCl}))$ to $+1.8 \mathrm{~V} /(\mathrm{Ag} / \mathrm{AgCl})$ for 20 cycles in dichloromethane containing $0.1 \mathrm{M} \mathrm{TBAPF}_{6}$ and $2 \times 10^{-4} \mathrm{M}$ (T-IFDK-T) monomer. The working electrode was glassy carbon and the electrochemical cell was de-aerated with $\mathrm{N}_{2}$. Fig. 1 displays the typical electropolymerization plot of (T-IFDK-T).

During the first cycle, by increasing the applied potential, current

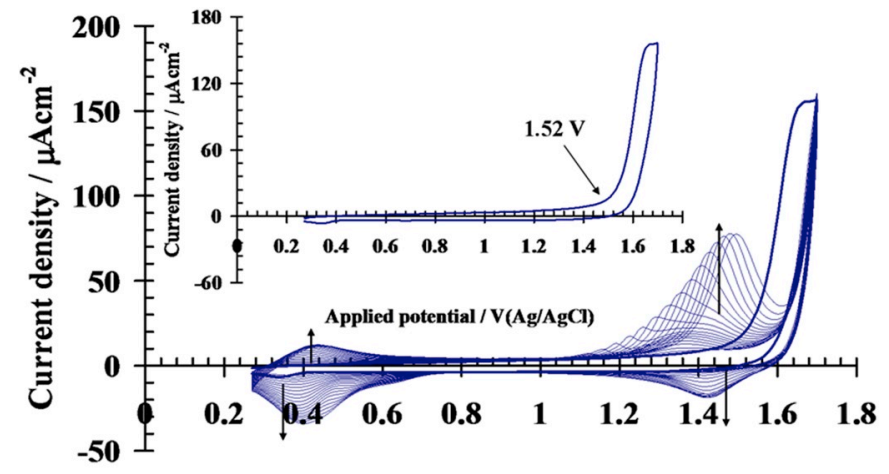

\section{Applied potential / V(Ag/AgCI)}

Fig. 1. Potentiodynamic electropolymerization plots of (T-IFDK-T) recorded in dichloromethane $0.1 \mathrm{M} \mathrm{TBAPF}_{6}$ and $2 \times 10^{-4} \mathrm{M}$ of monomer at a scan rate of $100 \mathrm{mV} / \mathrm{s}$. Inset: Cyclic voltammetry of monomer.

significantly increases starting from $1.52 \mathrm{~V} /(\mathrm{Ag} / \mathrm{AgCl})$, which corresponds to the monomer oxidation onset. Note that this oxidation potential is higher than that of non-functionalized indenofluorene [16] indicating the electron-withdrawing characteristics of carbonyl groups. An oxidation peak at $1.67 \mathrm{~V} /(\mathrm{Ag} / \mathrm{AgCl})$ corresponding to the radical cation formation at the electrode/electrolyte interface is recorded by switching the working electrode potential toward the anodic direction. Also, the peak value is higher than that of non-functionalized indenofluorenes [16]. The second cycle evidences an oxidation onset at around $1.20 \mathrm{~V} /(\mathrm{Ag} / \mathrm{AgCl})$. This value is lower than the oxidation onset of the monomer, thus suggesting the formation of the polymer onto working electrode. Furthermore, the polymer displays an oxidation peak at around $1.36 \mathrm{~V} /(\mathrm{Ag} / \mathrm{AgCl})$. As the number of cycles increases, the thickness of the polymeric film increases as well, influencing the redox reaction as suggested by the anodic shift of the oxidation peak [38]. Current density increases with the number of cycles and the oxidation peak becomes more prominent. By inverting the scan direction, a first cathodic process is noticed at $1.42 \mathrm{~V} /(\mathrm{Ag} / \mathrm{AgCl})$ which indicates that a partial dedoping process occurs. A quasi-reversible redox process is also observed at $0.4 \mathrm{~V} /(\mathrm{Ag} / \mathrm{AgCl})$. Based on these observations, (T-IFDK-T) electropolymerizes according to the standard mechanism proposed for most of the heterocyclic compounds [39].

\subsection{AFM analysis}

In order to investigate the morphological features of poly(IFDKT2), homogeneous and adherent thin films were deposited potentiostatically onto flat ITO/PET electrodes. The electrodeposition of poly (IFDK-T2) was performed by applying $2.2 \mathrm{~V} /(\mathrm{Ag} / \mathrm{AgCl})$. Fig. 2a and Fig. $2 \mathrm{~b}$ display the top view morphology in $2 \mathrm{D}$ and $3 \mathrm{D}$ configurations of poly(IFDK-T2) referred to a $10 \mu \mathrm{m} \times 10 \mu \mathrm{m}$ area. Poly(IFDK-T2) film surface appears granular with an average grain height around $190 \mathrm{~nm}$ and a root mean square of $52 \mathrm{~nm}$ and an average roughness of $40 \mathrm{~nm}$.

The same sample was used for the experimental determination of the film thickness. Fig. 3 shows the 3D image of poly(IFDK-T2) film recorded close to manually made scratches. Fig. 3a represents the scratch profile and Fig. 3b the 3D view. For the estimation of film thickness, the cross section profiles were built perpendicularly to the scratch over the entire surface and the height drop values were statistically processed and analysed.<smiles>CC(C)CC(C)C(C)(C)C</smiles>

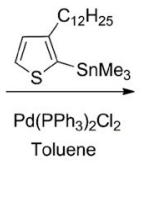

Scheme 1. Synthetic routes to T-IFDK-T and the corresponding electropolymerization protocol. 


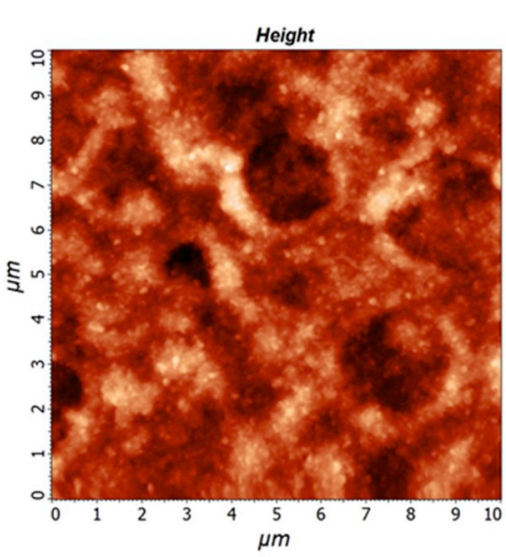

a)

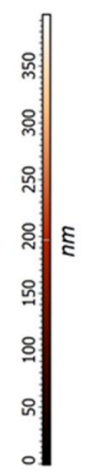

b)

Fig. 2. AFM photographs of a poly(IFDK-T2) thin film electrodeposited onto ITO/PET flat electrodes. a) 2D and b) 3D images.

By analysing the cross sections data of poly(IFDK-T2) by means of the histogram of the points height on the film-scratch (here not reported), the experimental thickness of $438 \mathrm{~nm}$ was extracted. This value was compared with theoretical thickness of almost $510 \mathrm{~nm}$ calculated by using the Faraday's law, in order to evaluate the faradaic efficiency of the electropolymerization processes [7]. By considering the charge circulated during the electrochemical deposition, (T-IFDK-T) electropolymerized with a Faradaic efficiency of $85 \%$. This value is higher than the electrochemical yield of polyindenofluorene [40].

\subsection{Optical and electro-optical properties}

In order to gain a deeper insight into the optical properties of the new polymeric system, several thin films were electrodeposited onto transparent and flexible ITO/PET working electrodes. Absorption spectra were recorded in the UV-Vis range and plotted in Fig. 4. As it can be seen, poly(IFDK-T2) absorbs in the whole explored wavelength range. In particular, it shows a higher intensity peak at $354 \mathrm{~nm}$ and a wide absorption shoulder between 500 and $650 \mathrm{~nm}$. The lower energy transition in poly(IFDK-T2) can be assigned to the HOMO-LUMO transition, as confirmed by DFT simulations (see Section 4.6). High energy transitions at around $355 \mathrm{~nm}$ can be ascribed to $\pi-\pi^{*}$ transitions into delocalized blackbone states.

The analysis of the photo-transitions and the optical band gaps of the polyindenofluorene-based thin films were determined by using the Tauc's law:

$\alpha(\nu)=\frac{A\left(h \nu-E_{g}\right)^{n}}{h \nu}$

where $\alpha(\nu)$ is the optical absorption coefficient, $h$ is the Planck constant,

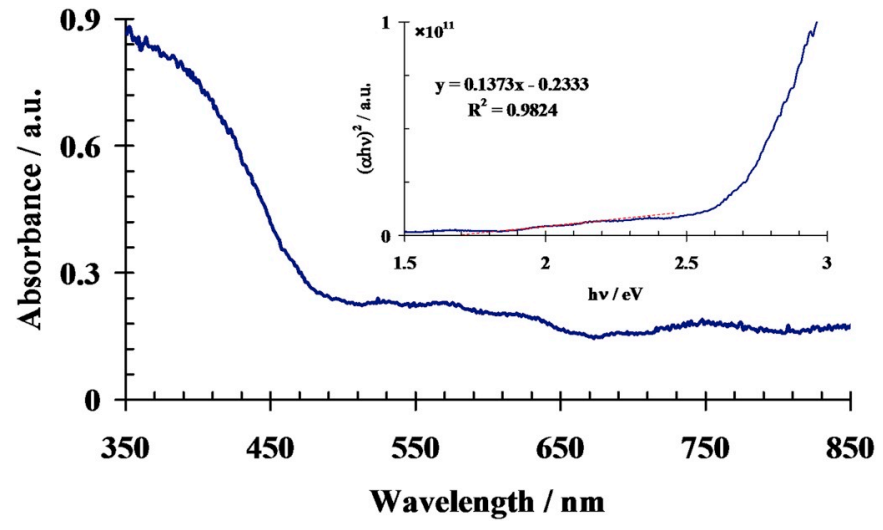

Fig. 4. Absorption spectrum of poly(IFDK-T2). Inset: elaboration by Tauc's law of poly(IFDK-T2) absorption spectrum.

$\nu$ is the frequency of the incident light, $A$ is a constant, $E_{\mathrm{g}}$ is the optical band gap and $n$ is a power coefficient which assumes different values according to the optical transitions. Under the hypothesis of direct optical transitions and by extrapolating the linear part of the $(\alpha h \nu)^{2}$ vs $h \nu$ to $(\alpha h \nu)^{2}=0$, optical band gap of $1.70 \mathrm{eV}$ was calculated for poly (IFDK-T2) (see inset of Fig. 4).

The modulation of the optical response under an applied electric field was evaluated by using a two electrode quartz cell and by applying different voltages between the polymeric film and the counter electrode in a solution of dichloromethane containing $0.1 \mathrm{M} \mathrm{TBAPF}_{6}$. Fig. 5a shows the absorbance against wavelength of poly(IFDK-T2) under voltages between $+1.7 \mathrm{~V}$ and $-1.0 \mathrm{~V}$ and Fig. $5 \mathrm{~b}$ shows a 3D view of

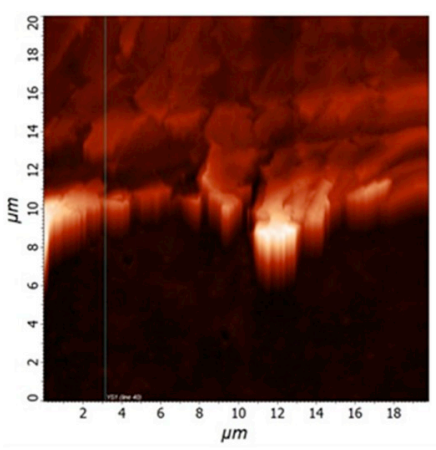

a)
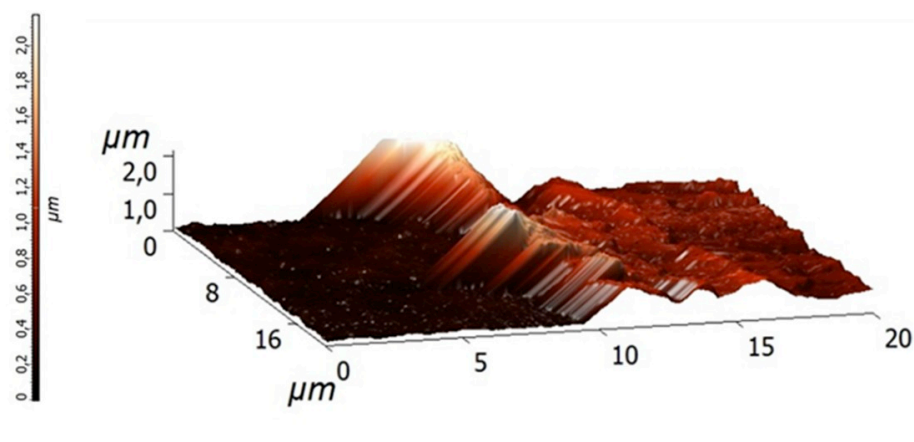

b)

Fig. 3. AFM images of a) poly(IFDK-T2) scratch profile and b) poly(IFDM-T2) 3D scratch profile. 


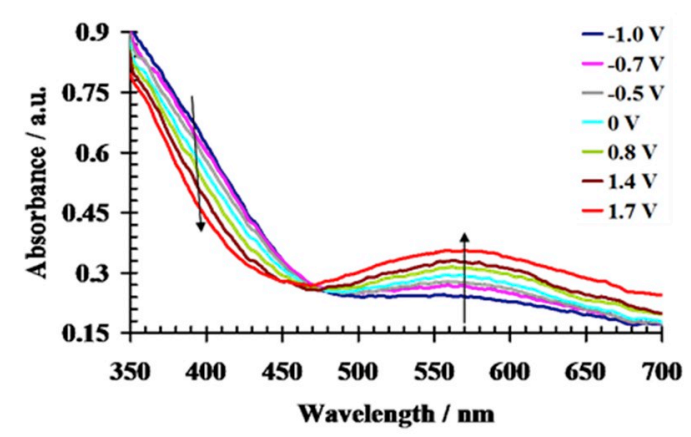

a)

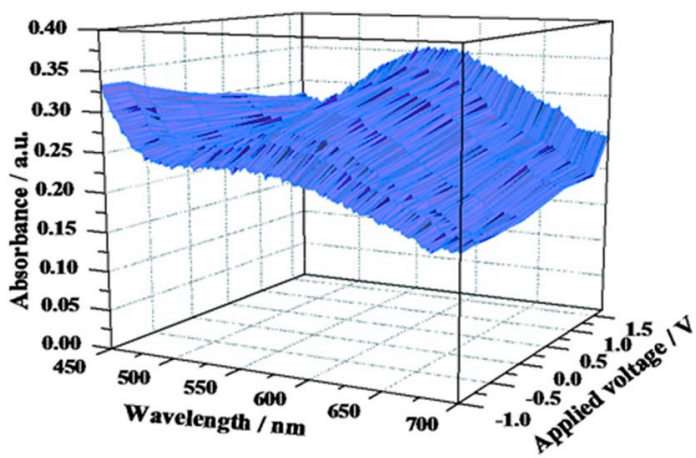

b)

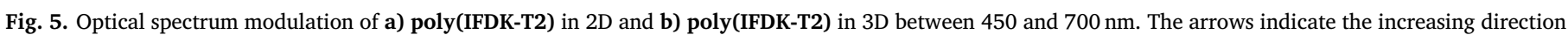
of the applied voltage.

the plot in a wavelength range between 450 and $700 \mathrm{~nm}$.

Poly(IFDK-T2) shows a variation of absorption spectra under the applied voltages. In particular, a hyperchromic shift is noticed by switching from oxidation to reduction voltages in the wavelength range between 350 and $460 \mathrm{~nm}$ and a hypochromic shift is noticed by switching from oxidation to reduction voltages in the wavelength range between 460 and $700 \mathrm{~nm}$. As the polymer is oxidized, the intensities of the $\pi-\pi^{*}$ transitions decrease while the intensities of the charge carrier bands at 500-700 nm increase due to polaron formation [41]. 3D absorption spectra of poly(IFDK-T2) are shown in Fig. 5b. The spectral changes of the polymer in response to applied different potentials were clearly observed.

\subsection{Electrochemical characterization}

Poly(IFDK-T2) films deposited onto glassy carbon electrodes were characterized by means of cyclic voltammetry (CV) in a solution made of $0.1 \mathrm{M} \mathrm{TBAPF}_{6}$ in $\mathrm{CH}_{2} \mathrm{Cl}_{2}$ by applying a potential scan rate of $100 \mathrm{mV}$ / $\mathrm{s}$ under $\mathrm{N}_{2}$ pressure. Experiments were performed starting from the open circuit values up to $2.0 \mathrm{~V} /(\mathrm{Ag} / \mathrm{AgCl})$. The reverse scan explored the cathodic branch down to $-2.0 \mathrm{~V} /(\mathrm{Ag} / \mathrm{AgCl})$. Fig. 6 shows the cyclic voltammogram of poly(IFDK-T2) thin film. The current vs potential plot evidences multiple redox activity. The forward anodic scan exhibits a potential oxidation onset at $1.24 \mathrm{~V} /(\mathrm{Ag} / \mathrm{AgCl})$ and two anodic peaks at $1.40 \mathrm{~V} /(\mathrm{Ag} / \mathrm{AgCl})$ and $1.80 \mathrm{~V} /(\mathrm{Ag} / \mathrm{AgCl})$, corresponding to the anionic doping and to the overoxidation of the polymer, respectively, due to anions migration from the solution to the polymeric matrix. The potential oxidation onset is lower than that of the monomer, which is a confirmation of the successful deposition of the polymeric film [42]. The reverse scan evidences four cathodic peaks located at $0.47,-0.50$, -0.66 and $-1.0 \mathrm{~V} /(\mathrm{Ag} / \mathrm{AgCl})$, respectively. The onset of reduction potential is calculated at $-0.40 \mathrm{~V} /(\mathrm{Ag} / \mathrm{AgCl})$. The first cathodic peak

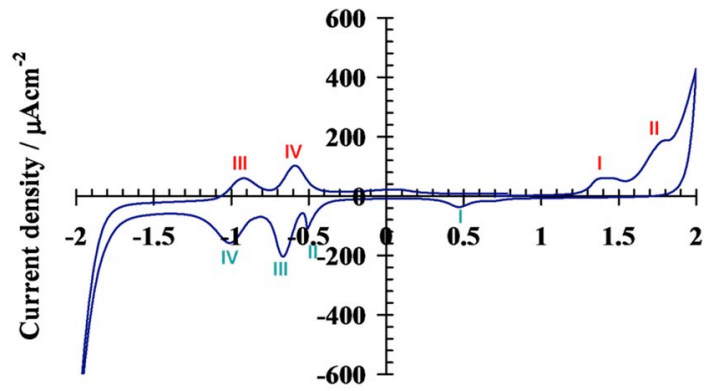

Applied potential / V(Ag/AgCl)

Fig. 6. Cyclic voltammogram of poly(IFDK-T2) recorded in $0.1 \mathrm{M} \mathrm{TBAPF}_{6}$ in $\mathrm{CH}_{2} \mathrm{Cl}_{2}$ at $100 \mathrm{mVs}^{-1}$. may be related to the expulsion of anions from the polymeric matrix corresponding to the discharging of the poly(IFDK-T2). The peak at $-1.0 \mathrm{~V} /(\mathrm{Ag} / \mathrm{AgCl})$ may be ascribed to negative charging processes due to cation insertion. Two anodic peaks at -0.92 and $-0.6 \mathrm{~V} /(\mathrm{Ag} / \mathrm{AgCl})$ are evidenced by inverting the potential scan toward the anodic direction, characterized by comparable current values with respect to the relative cathodic peaks. This result suggests the quasi-reversibility of the doping processes.

Cyclic voltammetry experiments provided poignant information about the polymers electron affinity (EA) and ionization potential (IP). The difference between IP and EA represents the electrochemical band gap, $E_{g, e c h}$ of the polymers. Equations (2) and (3) were used to calculate IP and EA with respect to vacuum level [46].

$I P=-E_{\text {onset }, o x}-4.5$

$E A=-E_{\text {onset,red }}-4.5$

where both $E_{\text {onset,ox }}$ and $E_{\text {onset,red }}$ are referred to normal hydrogen electrode (NHE).

Thus, poly(IFDK-T2) has an ionization potential of $-5.94 \mathrm{eV}$ and electron affinity of $-4.30 \mathrm{eV}$ which suggests a good stability with respect to $\mathrm{O}_{2} / \mathrm{H}_{2} \mathrm{O}$ [18]. Thus, an electrochemical band gap of $1.64 \mathrm{eV}$ is calculated. Table 1 summarizes the electrochemical and optical results, where HOMO is approximated at IP and LUMO is calculated as the difference between HOMO and the optical band gap.

\subsection{Theoretical analysis}

Table 2 summarizes theoretical IPs and EAs, transport gaps (IP-EA), and excitation energies of IFDK-2T monomer through tetramer in $\mathrm{CH}_{2} \mathrm{Cl}_{2}$. The IPs of dimer through tetramer differ only by $0.03 \mathrm{eV}$ and are about $0.4 \mathrm{eV}$ lower than that of the monomer. This shows that the results are convergent to the polymer value already at the dimer stage. The calculated difference between monomer and polymer is slightly larger than the difference between onsets of oxidation of $0.28 \mathrm{~V}$ (see above).

The first EAs of the oligomers, including the monomer, differ by only $0.08 \mathrm{eV}$ with a slight tendency of odd number oligomers having higher EAs than even-numbered ones. As there is no increase in EA with chain length, the EAs of the oligomers are the same as that of the polymer. With the $6-31+\mathrm{G}^{*}$ basis set, EA1 of the tetramer is $3.9 \mathrm{eV}$. Some geometry relaxation is likely to occur on the time scale of electrochemical reduction. This can be accounted for by optimization of the structure of the anion which increases EA1 by $0.2 \mathrm{eV}$, bringing it close to the experimental value of $4.3 \mathrm{eV}$.

The reason for the almost constant IPs and constant EA1s is partial localization of the valence and complete localization of the conduction band (Fig. 7). As the electron accepting units are isolated from each 
Table 1

Electrochemical and optical characteristics of poly(IFDK-T2).

\begin{tabular}{|c|c|c|c|c|c|c|c|c|}
\hline POLYMER & $\begin{array}{l}E_{\text {onset }, o x} \\
\text { [V/AgAgCl] }\end{array}$ & $\begin{array}{l}E_{\text {onset, }, \text { red }} \\
\text { [V/AgAgCl] }\end{array}$ & $\begin{array}{l}\text { IP } \\
{[\mathrm{eV}]}\end{array}$ & $\begin{array}{l}\text { EA } \\
{[\mathrm{eV}]}\end{array}$ & $\begin{array}{l}E_{g, e c h} \\
{[\mathrm{eV}]}\end{array}$ & $\begin{array}{l}\text { HOMO } \\
{[\mathrm{eV}]}\end{array}$ & $\begin{array}{l}\text { LUMO } \\
{[\mathrm{eV}]}\end{array}$ & $\begin{array}{l}E_{g, o p t} \\
{[\mathrm{eV}]}\end{array}$ \\
\hline & 1.24 & -0.40 & -5.945 & -4.305 & 1.64 & -5.945 & -4.245 & 1.70 \\
\hline
\end{tabular}

Table 2

$\triangle$ SCF IPs and EAs, transport gaps (IP-EA), and excitation energies of IFDK-2T oligomers with 1-4 repeat units in $\mathrm{CH}_{2} \mathrm{Cl}_{2}$.

\begin{tabular}{llllll}
\hline & IP & EA & IP-EA & $\mathrm{E}_{\mathrm{H}-\mathrm{L}} \mathrm{eV} \mathrm{nm} \mathrm{(osc)}$ & $\mathrm{E}_{\pi-\pi^{*}} \mathrm{eV} \mathrm{nm}(\mathrm{osc})$ \\
\hline Monomer & 6.52 & 3.64 & 2.88 & $2.31537(0.09)$ & $3.65340(0.97)$ \\
Dimer & 6.11 & 3.59 & 2.52 & $2.18568(0.40)$ & $3.13396(2.13)$ \\
Trimer & 6.13 & 3.67 & 2.46 & $2.12583(0.50)$ & $3.08409(4.42)$ \\
Tetramer & 6.10 & 3.61 & 2.49 & $2.12586(0.79)$ & $3.06405(5.86)$ \\
\hline
\end{tabular}

other, several consecutive reductions are predicted. The tetramer, for instance can accommodate up to 4 additional electrons with constant binding energies between 3.8 and $3.9 \mathrm{eV}$. The fifths EA, adding a second electron to one of the units is still positive by $2.37 \mathrm{eV}$.

As anions are air stable when the EA of the polymer is $\sim 4.0 \mathrm{eV}$ [43], these results suggest that Poly(IFDK-2T) can accommodate one negative charge per repeat in ambient conditions.

Optical spectra (Fig. 8) likewise converge rapidly with oligomer size. There is almost no difference in absorption peaks of trimer and tetramer apart from oscillator strength increase. The polymer spectrum can therefore be predicted to consist of two principle features at $\sim 590$ and $405 \mathrm{~nm}$. The lowest allowed excited state is the HOMO-LUMO transition. The oscillator strength (f) of 0.77 for the tetramer is relatively low because localization of the conduction band on indenofluorene and partial localization of the valence band on bithiophene result in small spatial overlap and a small transition dipole moment. The main feature of the spectrum ( $f=5.86$ for the tetramer) excites electrons into higher lying $\pi^{*}$-orbitals that are delocalized. The spectrum of poly(IFDK-2T) differs therefore qualitatively from those of homopolymers like for instance polythiophene, which exhibit only one band - a strong HOMO-LUMO absorption. In donor-acceptor polymers with strong acceptors HOMO-LUMO gaps are reduced at the expense of oscillator strength [31]. The consequence of localization for charge

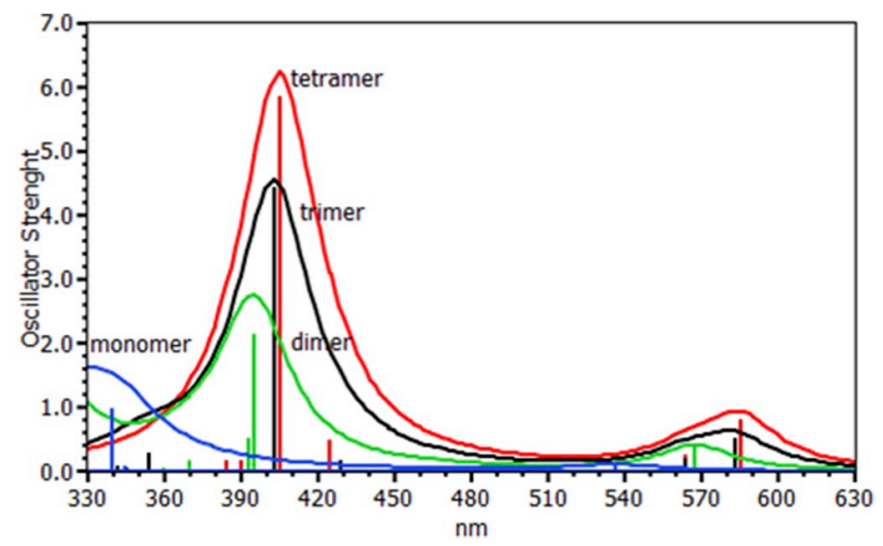

Fig. 8. - Absorption spectra of IFDK-2T oligomers.

transport is low charge carrier (hole and electron) mobility along the polymer backbone. Hence, the present systems behave more like molecular crystals than like polymers and high mobilities require good crystallinity and efficient interchain hopping.

Fig. 9 compares spectra of neutral and oxidized 4-(IFDK-2T) with the wB97X-D functional. The range-separated hybrid functional was employed for this purpose because the low energy polaron band is practically a pure charge transfer state which global hybrids underestimate dramatically. The wB97X-D functional predicts the first absorption of the cation at $854 \mathrm{~nm}$. The higher energy absorptions are similar in energy and in character to the $\pi-\pi^{*}$ transitions of the neutral form with half of the oscillator strength because they arise largely from the single electron (SOMO-LUMO $+\mathrm{X}$ ) transition. This explains the experimentally observed decrease in intensity in this region. A new band that arises from a mixture of various electronic transitions at
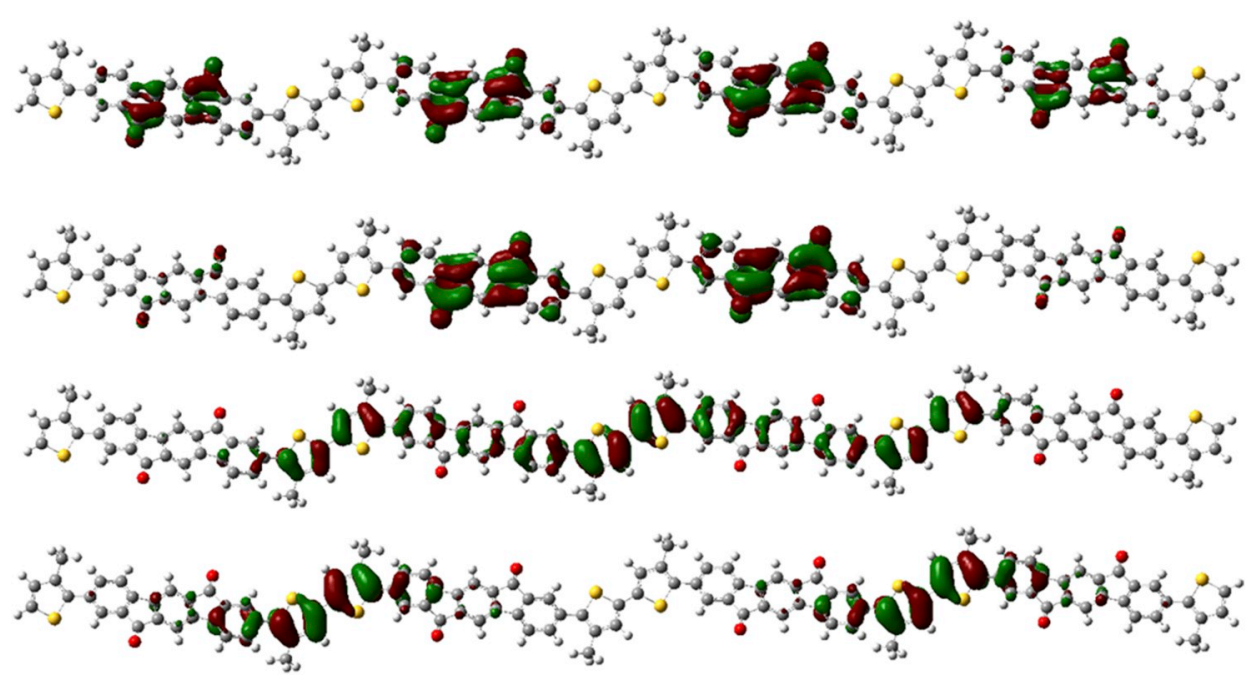

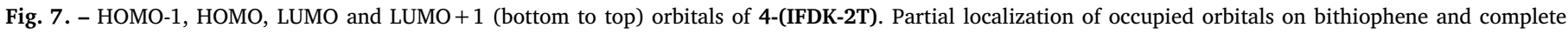
localization of unoccupied orbitals on indenofluorene units is clearly visible. 


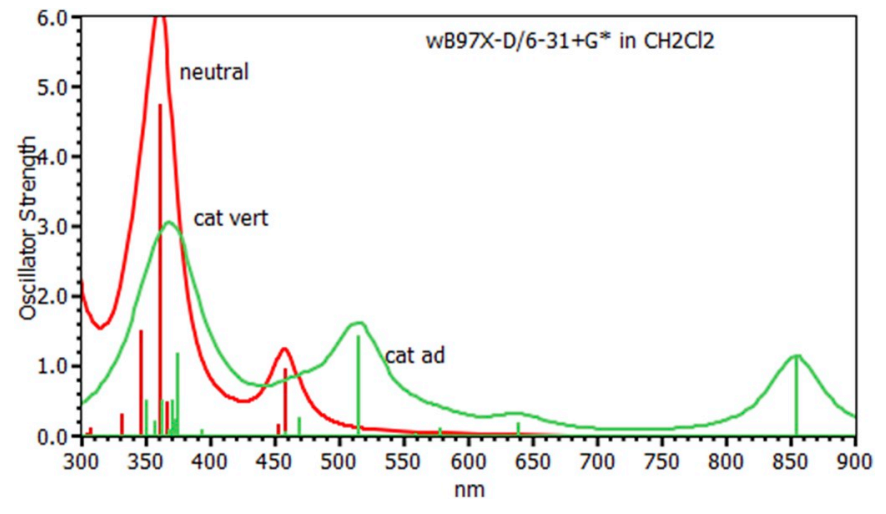

Fig. 9. - Absorption spectra of neutral and oxidized 4-IFDK-2T.

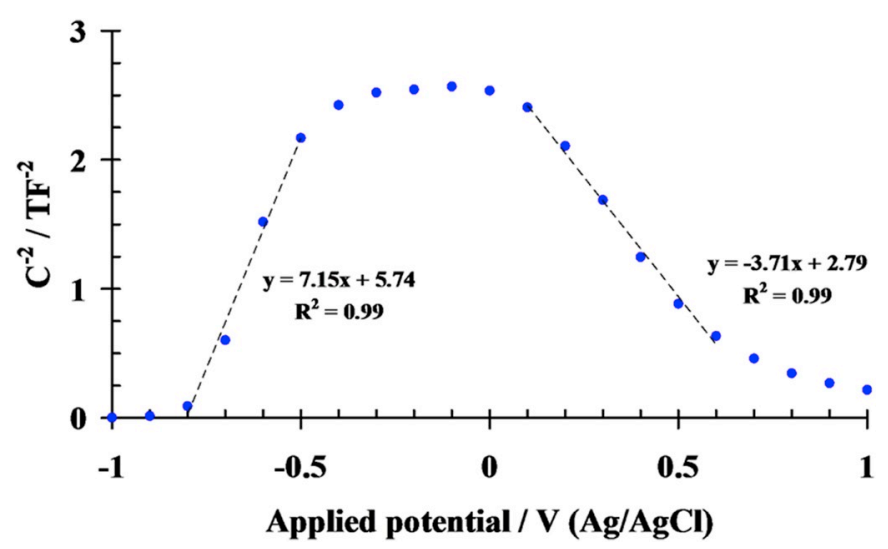

Fig. 10. - Mott-Schottky plots of poly(IFDK-T2) recorded in $0.1 \mathrm{M} \mathrm{TBAPF}_{6}$ in $\mathrm{CH}_{2} \mathrm{Cl}_{2}$ at $0.1 \mathrm{kHz}$.

$515 \mathrm{~nm}$. This feature within the uncertainty of our prediction rationalizes the increase in intensity in the experimental spectrum upon oxidation at around $570 \mathrm{~nm}$. The agreement between theoretical and experimental spectra confirms therefore successful polymerization and doping.

\subsection{Mott-Schottky analysis}

The model of inorganic semiconductor/electrolyte interface was applied in order to get information about the semiconducting properties of poly(IFDK-T2) thin films. Mott-Schottky theory was considered and some fundamental assumptions were done. Under the hypothesis of: absence of surface states and considering the space charge capacitance $\left(\mathrm{C}_{\mathrm{sc}}\right)$ lower than both Helmholtz double layer $\left(\mathrm{C}_{\mathrm{H}}\right)$ and Gouy-Chapman $\left(\mathrm{C}_{\mathrm{G}}\right)$ capacitances, the total capacitance can be approximated to the $\mathrm{C}_{\mathrm{sc}}$. Potentiodynamic electrochemical impedance spectroscopy (PDEIS) technique was used for detecting the dependence of $C_{S C}^{-2}$ of polymeric films as a function of the applied potential, V. The investigated potential range was between $+1.0 \mathrm{~V} /(\mathrm{Ag} / \mathrm{AgCl})$ and $-1.0 \mathrm{~V} /(\mathrm{Ag} / \mathrm{AgCl})$, where the polymer showed redox activity. Fig. 10 represents the $\mathrm{C}_{\mathrm{sc}}{ }^{-2}$ $v s \mathrm{~V}$ of poly(IFDK-T2) at $0.1 \mathrm{kHz}$.

P(IFDK-T2) exhibits some portions characterized by a linear

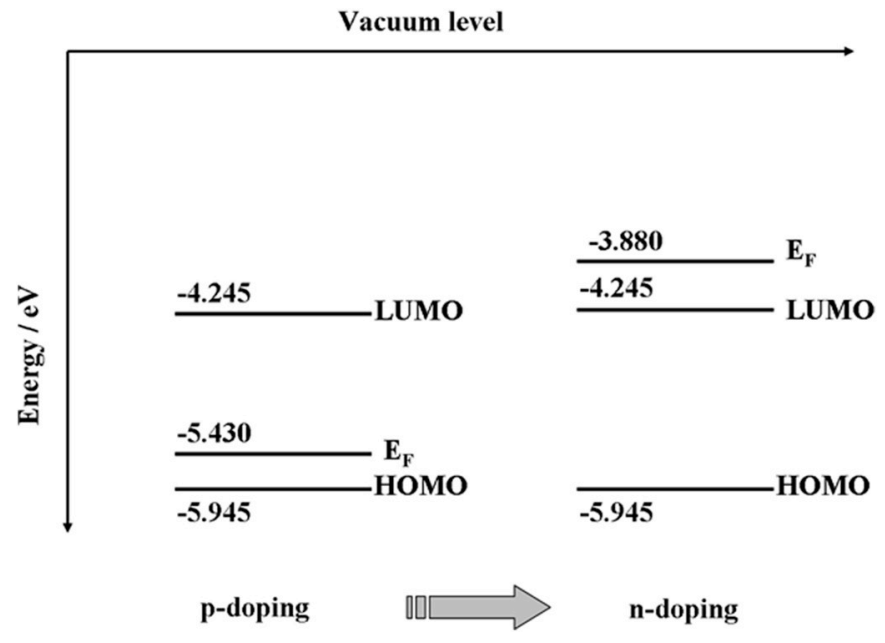

Fig. 11. - Energy levels diagrams of poly(IFDK-T2).

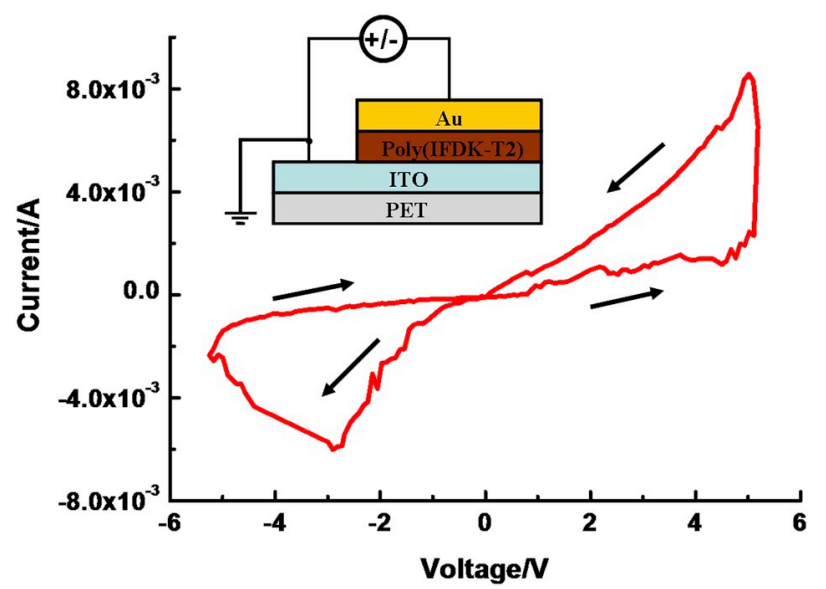

Fig. 12. - Typical I-V characteristic of the fabricated PET/ITO/poly(IFDK-T2)/ Au memristor. The inset shows the memristor structure and the electrical arrangement employed for the measurements.

dependence of $\mathrm{C}_{\mathrm{sc}}{ }^{-2} v s \mathrm{~V}$ with both negative and positive slopes; this linearity confirms the formation of a space charge layer at the semiconductor side. In particular, a linear portion with negative slope is evidenced in a potential range between $0.1 \mathrm{~V} /(\mathrm{Ag} / \mathrm{AgCl})$ and $0.6 \mathrm{~V} /$ $(\mathrm{Ag} / \mathrm{AgCl})$. A positive slope in a potential range between $-0.4 \mathrm{~V} /(\mathrm{Ag} /$ $\mathrm{AgCl})$ and $-0.8 \mathrm{~V} /(\mathrm{Ag} / \mathrm{AgCl})$ is also recorded. This ambipolar feature suggests that poly(IFDK-T2) easily switches from p-type to n-type semiconducting behaviour under suitable electric fields. This confirms the results obtained by cyclic voltammetry which revealed both anionic and cationic doping in the same explored potential range. By considering the Mott-Schottky equation [48]:

$\frac{1}{C_{S C}^{2}}=\frac{2}{\left(\varepsilon \varepsilon_{0} A^{2} e N\right)}\left(V-V_{F B}-\frac{k_{B} T}{e}\right)$

where $\varepsilon$ is the relative permittivity of the polymer, $\varepsilon_{0}$ is the vacuum permittivity, A is the electrode area, $e$ is the electron charge, $N$ is the

Table 3

Semiconducting properties of poly(IFDK-T2).

\begin{tabular}{|c|c|c|c|c|c|c|c|c|}
\hline Polymer & \multicolumn{4}{|l|}{ p-doping } & \multicolumn{4}{|l|}{ n-doping } \\
\hline Poly (IFDK-T2) & $-3.71 \times 10^{12}$ & $2.58 \times 10^{21}$ & 0.750 & 0.725 & $7.15 \times 10^{12}$ & $1.34 \times 10^{21}$ & -0.80 & -0.825 \\
\hline
\end{tabular}

${ }^{\mathrm{a}}$ Ref. $=\mathrm{V}$ vs. $\mathrm{Ag} / \mathrm{AgCl}$. 
charge carriers density, $\mathrm{V}$ is applied potential, $\mathrm{V}_{\mathrm{FB}}$ is the flat band potential, $\mathrm{k}_{\mathrm{B}}$ is the Boltzmann's constant and $\mathrm{T}$ is the absolute temperature, and by fitting the linear portions, interesting parameters such as the flat band potential and charge carriers density were acquired.

Table 3 summarizes the experimental results obtained by elaborating $\mathrm{C}_{\mathrm{sc}}{ }^{-2}$ vs $\mathrm{V}$ plots, considering: $\varepsilon=3$ [44], $\mathrm{A}=0.07 \mathrm{~cm}^{2}$, $\mathrm{k}_{\mathrm{B}} \mathrm{T}=26 \mathrm{meV}, \varepsilon_{0}=8.85 \times 10^{-14} \mathrm{Fcm}^{-1}, e=1.602 \times 10^{-19} \mathrm{C}$.

As in the condition of flat band potential there is no charge transfer, it is possible to consider $\mathrm{V}_{\mathrm{FB}}=\mathrm{V}_{\mathrm{F}}$ where $\mathrm{V}_{\mathrm{F}}$ is the Fermi level of the organic semiconductors. The location of Fermi level with respect to vacuum $\left(E_{F}\right)$ and the location of HOMO and LUMO levels, reported in Fig. 11, confirmed the p-type and n-type semiconducting behaviour of the polymer.

An interesting result is evidenced when the polymer is n-type doped. Poly(IFDK-T2) behaves like a strongly degenerated n-type semiconductor as demonstrated by the position of $E_{F}$ which is higher than LUMO level. This situation is in correlation with the inorganic degenerated n-type semiconductors, which are characterized by the Fermi level inside the conduction band. The reproducibility of the quasi-metallic behaviour of poly(IFDK-T2) was confirmed by further experiments repetitions.

\subsection{Memristors characterization}

Fig. 12 shows a typical I-V hysteresis curve of a $600 \mathrm{~nm}$-thick poly (IFDK-T2)-based memristor. The voltage was swept in the range from $5.2 \mathrm{~V}$ to $+5.2 \mathrm{~V}$, following the cycle described by the arrows. The device is initially in its high resistance state (HRS or OFF state). Under positive voltage sweep there is a gradual increase of the current, until a threshold voltage $\left(\mathrm{V}_{\mathrm{SET}}\right)$ of about $4.7 \mathrm{~V}$ is reached and a steep increase in the current, leading the device to the low resistance state (LRS or ON state), can be observed. During the negative voltage sweep, the device transforms back to the HRS at about $-4.7 \mathrm{~V}$. This behaviour is typical of a bipolar device and may be ascribed, as reported for others organic memristors, to the formation and rupture of Au filaments during operation $[49,50]$. An average of about 20 cycles was performed before failure of the devices, probably due to a lack of a current compliance imposed during operation. Memristive effect was observed in the absence of a preliminary forming cycle, which can be advantageous to practical applications. A voltage larger than $\pm 4.5 \mathrm{~V}$ needed to be applied, however, before seeing any evident effect. Thinner films required a lower applied voltage to show resistive switching, but failed after a few cycles due to excessive Joule heating.

The $\mathrm{R}_{\mathrm{OFF}} / \mathrm{R}_{\mathrm{ON}}$ ratio, measured at $-0.9 \mathrm{~V}$, was 4.05 .

\section{Conclusions}

Indenofluorene-based monomer (T-IFDK-T), functionalized with carbonyl moiety, is electrochemically polymerized for the first time via an anodic route. The stronger electron-withdrawing behaviour of carbonyl group allows the anodic polymerization at higher overpotential values with respect to indenofluorene. The investigation about the semiconducting properties reveals an ambipolar behaviour with a quasi metallic feature in the case of n-doped poly(IFDK-T2). This interesting result may be ascribed to the strong electron withdrawing behaviour of carbonyl functionalized polymer. The memristive behaviour of poly (IFDK-T2) was proved by fabricating and electrically characterizing mm-scale PET/ITO/poly(IFDK-T2)/Au memristors. The fabricated flexible memristive devices exhibit bipolar resistive switching properties with a $R_{\mathrm{OFF}} / \mathrm{R}_{\mathrm{ON}}$ ratio of 4.05 which needs to be improved for memory applications. However, the possibility of employing air-stable poly(IFDK-T2)-based memristors, without carrying out a prior forming process and without cautions due to the exposition to atmosphere, makes this material an interesting candidate for low cost flexible resistive random access memories.

\section{Declaration of interests}

The authors declare that they have no known competing financial interests or personal relationships that could have appeared to influence the work reported in this paper.

\section{Funding}

This research did not receive any specific grant from funding agencies in the public, commercial, or not-for-profit sectors.

\section{References}

[1] C. Zhang, T. Liu, W. Zeng, D. Xie, Z. Luo, Y. Sun, C. Yang, Thienobenzene-fused perylene bisimide as a non-fullerene acceptor for organic solar cells with a high open-circuit voltage and power conversion efficiency, Mater. Chem. Front. 1 (2017) 749.

[2] V. Figà, H. Derbal Habak, B. Kulyk, M. Abbate, Fluorescence quenching in hybrid solar cells based on electrodeposited ZnO, J. Optoelectron. Adv. Mater. 15 (2013) 954.

[3] G.J. Stec, A. Lauchner, Y. Cui, P. Nordlander, N.J. Halas, Multicolor electrochromic devices based on molecular plasmonics, ACS Nano 11 (3) (2017) 3254.

[4] M. Ozdemir, D. Choi, Y. Zorlu, B. Cosut, H. Kim, C. Kim, H. Usta, A new rod-shaped BODIPY-acetylene molecule for solution-processed semiconducting microribbons in n-channel organic field-effect transistors, New J. Chem. 41 (2017) 6232.

[5] A.M.A.A.A. AL-Mokaram, R. Yahya, M.M. Abdi, H.N.M. Ekramul Mahmud, The development of non-enzymatic glucose biosensors based on electrochemically prepared polypyrrole-chitosan-titanium dioxide nanocomposite films, Nanomaterials 7 (6) (2017) 129.

[6] Y. Nagai, H. Sasabe, J. Takahashi, N. Onuma, T. Ito, S. Ohisa, J. Kido, Highly efficient, deep-red organic light-emitting devices using energy transfer from exciplexes, J. Mater. Chem. C 5 (2017) 527.

[7] V. Figà, J. Luc, M. Baitoul, B. Sahraoui, NLO properties of polythiophenes galvanostatically electrodeposited on ITO glasses, J. Optoelectron. Adv. Mater. 10 (2008) 2123.

[8] V. Figà, J. Luc, B. Kulyk, M. Baitoul, B. Sahraoui, Characterization and investigation of NLO properties of some selected electrodeposited polythiophenes, J. Eur. Opt. Soc. - Rapid Publ. 4 (2009) 09016.

[9] V. Figà, C. Chiappara, F. Ferrante, M.P. Casaletto, F. Principato, S. Cataldo, Z. Chen, H. Usta, A. Facchetti, B. Pignataro, Symmetric naphthalenediimidequaterthiophenes for electropolymerized electrochromic thin films, J. Mater. Chem. C 3 (2015) 5985.

[10] V. Figà, Z. Essaidi, Influence of the electrodeposition conditions on the energetics of polypyrrole thin films, J. Optoelectron. Adv. Mater. 10 (2008) 3392.

[11] U. Scherf, E.J.W. List, Semiconducting polyfluorenes--towards reliable structure-property relationships, Adv. Mater. 14 (2002) 477.

[12] Y.C. Lo, H.C. Ting, Y.Z. Li, Y.H. Li, S.W. Liu, K.W. Huang, K.T. Wong, The synthesis, structure, and properties of 5,6,11,12-tetraarylindeno[1,2-b]fluorenes and their applications as donors for organic photovoltaic devices, Org. Chem. Front., Org. Chem. Front. 4 (2017) 675.

[13] J. Zhang, B. Zhao, Y. Mi, H. Liu, Z. Guo, G. Bie, W. Wei, C. Gao, Z. An, A new wide bandgap small molecular acceptor based on indenofluorene derivatives for fullerene-free organic solar cells, Dyes Pigments 140 (2017) 261.

[14] D. Thirion, C. Poriel, J. Rault-Berthelot, F. Barriere, O. Jeannin, (2,1-a)Indenofluorene derivatives: syntheses, X-ray structures, optical and electrochemical properties, Chem. Eur J. 16 (2010) 13646.

[15] D. Thirion, C. Poriel, R. Metivier, J. Rault-Berthelot, F. Barriere, O. Jeannin, Violetto-Blue tunable emission of aryl-substituted dispirofluorene-indenofluorene isomers by conformationally-controllable intramolecular excimer formation, Chem. Eur J. 17 (2011) 10272.

[16] C. Poriel, J.J. Liang, J. Rault-Berthelot, F. Barriere, N. Cocherel, A.M.Z. Slawin, D. Horhant, M. Virboul, G. Alcaraz, N. Audebrand, L. Vignau, N. Huby, G. Wantz, L. Hirsch, Dispirofluorene-indenofluorene derivatives as new building blocks for blue organic electroluminescent devices and electroactive polymers, Chem. Eur J. 13 (2007) 10055

[17] K.H. Lee, S.O. Kim, S. Kang, J.Y. Lee, K.S. Yook, J.Y. Lee, S.S. Yoon, Indenofluorenebased blue fluorescent compounds and their application in highly efficient organic light-emitting diodes, Eur. J. Org. Chem. 14 (2012) 2748.

[18] H. Usta, C. Risko, Z. Wang, H. Huang, M.K. Deliomeroglu, A. Zhukhovitskiy, A. Facchetti, T.J. Marks, Design, synthesis, and characterization of ladder-type molecules and polymers. Air-stable, solution-processable n-channel and ambipolar semiconductors for thin-film transistors via experiment and theory, J. Am. Chem. Soc. 131 (2009) 5586.

[19] M. Ozdemir, D. Choi, G. Kwon, Y. Zorlu, H. Kim, M.G. Kim, S.Y. Seo, U. Sen, M. Citir, C. Kim, H. Usta, Design, synthesis, and characterization of $\alpha, \omega$-disubstituted indeno[1,2-b]fluorene-6,12-dione-thiophene molecular semiconductors. Enhancement of ambipolar charge transport through synthetic tailoring of alkyl substituents, RSC Adv. 6 (2016) 212.

[20] R. Ozdemir, D. Choi, M. Ozdemir, G. Kwon, H. Kim, U. Sen, C. Kim, H. Usta, Ultralow bandgap molecular semiconductors for ambient-stable and solution-processable ambipolar organic field-effect transistors and inverters, J. Mater. Chem. C 5 (2017) 2368. 
[21] R. Ozdemir, D. Choi, M. Ozdemir, H. Kim, S.T. Kostakoglu, M. Erkartal, H. Kim, C. Kim, H. Usta, A solution-processable liquid-crystalline semiconductor for lowtemperature-annealed air-stable N-channel field-effect transistors, ChemPhysChem 18 (2017) 850.

[22] J.J. Yang, M.D. Pickett, X. Li, D.A. Ohlberg, D.R. Stewart, R.S. Williams, Memristive switching mechanism for metal/oxide/metal nanodevices, Nat. Nanotechnol. 3 (2008) 429.

[23] S. Yu, Y. Wu, R. Jeyasingh, D. Kuzum, H.-S.P. Wong, An electronic synapse device based on metal oxide resistive switching memory for neuromorphic computation, IEEE Trans. Electron Devices 58 (2011) 2729.

[24] H.S.P. Wong, H.-Y. Lee, S. Yu, Y.-S. Chen, Y. Wu, P.-S. Chen, B. Lee, F.T. Chen, M.J. Tsai, Metal-oxide RRAM, Proc. IEEE, vol. 100, 2012, p. 1951.

[25] R. Macaluso, M. Mosca, V. Costanza, A. D'Angelo, G. Lullo, F. Caruso, C. Calì, F. Di Franco, M. Santamaria, F. Di Quarto, Resistive switching behaviour in $\mathrm{ZnO}$ and $\mathrm{VO}_{2}$ memristors grown by pulsed laser deposition, Electron. Lett. 50 (2014) 262.

[26] V. Aglieri, A. Zaffora, G. Lullo, M. Santamaria, F. Di Franco, U. Lo Cicero, M. Mosca, R. Macaluso, Resistive switching in microscale anodic titanium dioxide-based memristors, Superlattice. Microst. 113 (2018) 135.

[27] T. Berzina, A. Smerieri, M. Bernabò, A. Pucci, G. Ruggeri, V. Erokhin, M.P. Fontana, Optimization of an organic memristor as an adaptive memory element, J. Appl. Phys. 105 (2009) 124515.

[28] Y. Chen, G. Liu, C. Wang, R. Li, W. Zhang, L. Wang, Polymer memristor for information storage and neuromorphic applications, Mater. Horiz. 1 (2014) 489.

[29] H. Usta, A. Facchetti, T. J. Marks, air-stable, solution-processable n-channel and ambipolar semiconductors for thin-film transistors based on the indenofluorenebis (dicyanovinylene) core, J. Am. Chem. Soc. 130 (2008) 8580.

[30] U. Salzner, A. Aydin, Improved prediction of properties of $\pi$-conjugated oligomers with range-separated hybrid density functionals, J. Chem. Theory Comput. 7 (8) (2011) 2568.

[31] U. Salzner, Effect of donor-acceptor substitution on optoelectronic properties of conducting organic polymers, J. Chem. Theory Comput. 10 (11) (2014) 4921.

[32] M. Cossi, V. Barone, B. Mennucci, J. Tomasi, Ab initio study of ionic solutions by a polarizable continuum dielectric model, Chem.l Phys. Lett. 286 (3) (1998) 253.

[33] M. Cossi, V. Barone, Time-dependent density functional theory for molecules in liquid solutions, J. Chem. Phys. 115 (2001) 4708.

[34] E.A. Reed, R.B. Weinstock, F. Weinhold, J. Chem. Phys. 83 (1985) 735.

[35] M.J. Frisch, G.W. Trucks, H.B. Schlegel, G.E. Scuseria, M.A. Robb, J.R. Cheeseman, G. Scalmani, V. Barone, B. Mennucci, G.A. Petersson, H. Nakatsuji, M. Caricato, H.P. Hratchian, A.F. Izmaylov, J. Bloino, G. Zheng, J.L. Sonneberg, M. Hada, M. Ehara, K. Toyota, R. Fukuda, J. Hasegawa, M. Ishida, T. Nakajima, Y. Honda, O. Kitao, H. Nakai, T. Vreven, J.A. Jr Montgomery, J.E. Peralta, F. Ogliaro, M. Bearpark, J.J. Heyd, E. Brothers, K.N. Kudin, V.N. Staroverov, R. Kobayashi, J. Normand, K. Raghavachari, A. Rendell, J.C. Burant, S.S. Iyengar, J. Tomasi, M. Cossi, N. Rega, J.M. Millam, M. Klene, J.E. Knox, J.B. Cross, V. Bakken, C. Adamo, J. Jaramillo, R. Gomperts, R.E. Stratmann, O. Yazyev, A.J. Austin, R. Cammi, C. Pomelli, J.W. Ochterski, R.L. Martin, K. Morokuma, V.G. Zakrzewski, G.A. Voth, P. Salvador, J.J. Dannenberg, S. Dapprich, A.D. Daniels, O. Farkas, J.B. Foresman, J.V. Ortiz, J. Cioslowski, D.J. Fox, Gaussian 09, Revision A.1, Gaussian, Inc., Wallinford, CT, 2009.

[36] M.J. Frisch, G.W. Trucks, H.B. Schlegel, G.E. Scuseria, M.A. Robb, J.R. Cheeseman, G. Scalmani, V. Barone, G.A. Petersson, H. Nakatsuji, X. Li, M. Caricato, A.V. Marenich, J. Bloino, B.G. Janesko, R. Gomperts, B. Mennucci, H.P. Hratchian, J.V. Ortiz, A.F. Izmaylov, J.L. Sonnenberg, Williams, F. Ding, F. Lipparini, F. Egidi,
J. Goings, B. Peng, A. Petrone, T. Henderson, D. Ranasinghe, V.G. Zakrzewski, J. Gao, N. Rega, G. Zheng, W. Liang, M. Hada, M. Ehara, K. Toyota, R. Fukuda, J. Hasegawa, M. Ishida, T. Nakajima, Y. Honda, O. Kitao, H. Nakai, T. Vreven, K. Throssell, J.A. Montgomery Jr., J.E. Peralta, F. Ogliaro, M.J. Bearpark, J.J. Heyd, E.N. Brothers, K.N. Kudin, V.N. Staroverov, T.A. Keith, R. Kobayashi, J. Normand, K. Raghavachari, A.P. Rendell, J.C. Burant, S.S. Iyengar, J. Tomasi, M. Cossi, J.M. Millam, M. Klene, C. Adamo, R. Cammi, J.W. Ochterski, R.L. Martin, K. Morokuma, O. Farkas, J.B. Foresman, D.J. Fox, Gaussian 16 Rev. B.01, Wallingford, CT, (2016).

[37] A.-R. Allouche, Gabedit—a graphical user interface for computational chemistry softwares, J. Comput. Chem. 32 (1) (2011) 174-182.

[38] S.M. Sayyah, M.M. El-Deeb, S.M. Kamal, R.E. Azooz, Electropolymerization of ophenylenediamine on Pt-electrode from aqueous acidic solution: kinetic, mechanism, electrochemical studies and characterization of the polymer obtained, J. Appl. Polym. Sci. 112 (2009) 3695.

[39] J. Roncali, Conjugated poly(thiophenes): synthesis, functionalization, and applications, Chem. Rev. 92 (1992) 711.

[40] J.R. Berthelot, C. Poriel, F. Justaud, F. Barrière, Anodic oxidation of indenofluorene. Electrodeposition of electroactive poly(indenofluorene), New J. Chem. 32 (2008) 1259.

[41] A. Aydin, I. Kaya, Electrochim. Acta 65 (2012) 104-114.

[42] S.S. Zade, M. Bendikov, From oligomers to Polymer: convergence in the HOMO - LUMO gaps of conjugated oligomers, Org. Lett. 8 (23) (2006) 5243.

[43] J. Dhar, U. Salzner, S. Patil, Trends in molecular design strategies for ambient stable n-channel organic field effect transistors, J. Mater. Chem. C 5 (30) (2017) 7404-7430.

[44] Y. Tamai, H. Ohkita, H. Benten, S. Ito, Exciton diffusion in conjugated polymers: from fundamental understanding to improvement in photovoltaic conversion efficiency, J. Phys. Chem. Lett. 6 (17) (2015) 3417.

[45] V. Aglieri, G. Lullo, M. Mosca, R. Macaluso, A. Zaffora, F. Di Franco, M. Santamaria, U. Lo Cicero, L. Razzari, Forming-free and self-rectifying resistive switching effect in anodic titanium dioxide-based memristors, IEEE 4th International Forum on Research and Technology for Society and Industry (RTSI), 10 - 13 September 2018, Palermo (Italy), Pag. 540, 2018.

[46] R. Cervini, X.-C. Li, G.W.C. Spencer, A.B. Holmes, S.C. Moratti, R.H. Friend, Electrochemical and optical studies of PPV derivatives and poly(aromatic oxadiazoles), Synth. Met. 84 (1997) 359.

[47] S. Bhandari, M.S. Cheung, E. Geva, L. Kronik, B.D. Dunietz, Fundamental gaps of condensed-phase organic semiconductors from single-molecule calculations using polarization-consistent optimally tuned screened range-separated hybrid functionals, J. Chem. Theory Comput. 14 (12) (2018) 6287-6294.

[48] M. Metikoš-Hukovic, S. Omanovic, A. Jukic, Impedance spectroscopy of semiconducting films on tin electrodes, Elec, Acta 45 (1999) 977-986.

[49] B. Cho, J.-M. Yun, S. Song, Y. Ji, D.-Y. Kim, T. Lee, Direct observation of Ag filamentary paths in organic resistive memory devices, Adv. Funct. Mater. 21 (2011) 3976.

[50] G.T.S. Howa, N.A. Talika, Y.B. Karb, H. Nakajimad, S. Tunmeed, G.B. Tonga, Multiple resistive switching behaviours of $\mathrm{CH}_{3} \mathrm{NH}_{3} \mathrm{PbI}_{3}$ perovskite film with different metal electrodes, Appl. Surf. Sci. 473 (2019) 194.

[51] J.-D. Chai, M. Head-Gordon, Long-range corrected hybrid density functionals with damped atom-atom dispersion corrections, Phys. Chem. Chem. Phys. 10 (44) (2008) 6615-6620. 